\title{
TU/e EmonOWEN

\section{A database approach for materials selection for hydrogen storage in aerospace technology}

Citation for published version (APA):

Coppola, C. M., Tolbatov, I., Tranca, I., Coletti, C., Marrone, A., Storchi, L., Di Profio, P., Re, N., Kazandjian, M. V., Pellecchia, A., Longo, S., Gaastra-Nedea, S. V., Fernandez-Villace, V., \& Longo, J. (2019). A database approach for materials selection for hydrogen storage in aerospace technology. Rendiconti Lincei. Scienze Fisische e Naturali, 30(2), 287-296. https://doi.org/10.1007/s12210-019-00805-9

\section{Document license:}

TAVERNE

DOI:

10.1007/s12210-019-00805-9

Document status and date:

Published: 01/06/2019

\section{Document Version:}

Publisher's PDF, also known as Version of Record (includes final page, issue and volume numbers)

\section{Please check the document version of this publication:}

- A submitted manuscript is the version of the article upon submission and before peer-review. There can be important differences between the submitted version and the official published version of record. People interested in the research are advised to contact the author for the final version of the publication, or visit the $\mathrm{DOI}$ to the publisher's website.

- The final author version and the galley proof are versions of the publication after peer review.

- The final published version features the final layout of the paper including the volume, issue and page numbers.

Link to publication

\section{General rights}

Copyright and moral rights for the publications made accessible in the public portal are retained by the authors and/or other copyright owners and it is a condition of accessing publications that users recognise and abide by the legal requirements associated with these rights.

- Users may download and print one copy of any publication from the public portal for the purpose of private study or research.

- You may not further distribute the material or use it for any profit-making activity or commercial gain

- You may freely distribute the URL identifying the publication in the public portal.

If the publication is distributed under the terms of Article $25 \mathrm{fa}$ of the Dutch Copyright Act, indicated by the "Taverne" license above, please follow below link for the End User Agreement:

www.tue.nl/taverne

Take down policy

If you believe that this document breaches copyright please contact us at:

openaccess@tue.nl

providing details and we will investigate your claim. 


\title{
A database approach for materials selection for hydrogen storage in aerospace technology
}

\author{
Carla Maria Coppola ${ }^{1}$ - I logann Tolbatov ${ }^{2} \cdot$ Ionut Claudiu Tranca $^{3} \cdot$ Cecilia Coletti $^{2} \cdot$ Alessandro Marrone $^{2}$. \\ Loriano Storchi ${ }^{2}$. Pietro Di Profio ${ }^{2}$ - Nazzareno $\mathrm{Re}^{2} \cdot$ Mher V. Kazandjian $^{4}$ - Antonello Pellecchia ${ }^{5}$. Savino Longo ${ }^{1}$. \\ Silvia Gaastra-Nedea ${ }^{6} \cdot$ Victor Fernandez-Villace $^{7} \cdot$ José Longo $^{8}$
}

Received: 25 March 2019 / Accepted: 26 April 2019 / Published online: 7 May 2019

(c) Accademia Nazionale dei Lincei 2019

\begin{abstract}
Hydrogen economy has been suggested as a possible green alternative to produce energy, also in the framework of transport applications. According to the specific transport means, different kinds of materials can be adopted. The choice of the most suitable materials should then be addressed according to a systematic analysis of available data. In this paper, together with the major physical storage technologies typically used for aerospace applications, additional possible candidates are suggested, namely clathrates hydrates and metal-organic frameworks (MOFs). They are chosen according to the specific features that are asked in the aerospace industry, such as high storage capacities, low weight and materials cost, high cyclability and full reversibility. To this scope, a comprehensive database based on a large set of information from literature (containing, for example, details on the synthesis processes, the operating temperatures and pressures, volumetric and gravimetric capacities) has been created, and specific tools have been developed to query the database. Indeed, the selection of the materials has been performed via an alternative database approach where the queries can be managed using a user-friendly tool, and potential materials can be selected based on any pool of desirable properties in quantitative terms. Essential information and characterization on theoretical and experimental data about these performing materials are provided and commented. As an example, in this paper, the case of clathrates hydrates is shown, and their potential impact is explored and characterized in this context, suggesting the most suitable synthesis processes.
\end{abstract}

Keywords Hydrogen storage $\cdot$ Porous materials $\cdot$ Transport $\cdot$ Aerospace $\cdot$ Database

\section{Introduction}

Carla Maria Coppola, Iogann Tolbatov and Ionut Claudiu Tranca equally contributed to this work.

This contribution is the written, peer-reviewed version of a paper presented at the Conference "Classical and quantum plasmas: matter under extreme conditions" held at Accademia Nazionale dei Lincei in Rome on April 5-6, 2018.

Carla Maria Coppola

carla.coppola@uniba.it

1 Dipartimento di Chimica, Università degli Studi di Bari, Via Orabona 4, 70126 Bari, Italy

2 Dipartimento di Farmacia, Università "Gabriele D'Annunzio", Chieti, Italy

3 Energy Technology, Eindhoven University of Technology, Eindhoven, The Netherlands

4 Leiden Observatory, Leiden University, PO Box 9513, 2300 RA Leiden, The Netherlands
Safety and sustainability in generating, transporting, and using energy are nowadays an increasing urge both for environmental and social reasons. Hydrogen storage technologies represent an important route in solving these problems. Having one of the highest energy content per unit weight

5 Dipartimento di Fisica, Università degli Studi di Bari, Via Orabona 4, 70126 Bari, Italy

6 Energy Technology, Eindhoven University of Technology, Eindhoven, The Netherlands

7 European Space Agency (ESTEC), Keplerlaan 1, 2201 AZ Noordwijk, The Netherlands

8 European Space Agency (ESRIN), Via Galileo Galilei, 00044 Frascati RM, Italia 
of any fuel (120 MJ/kg), hydrogen has found application as rocket fuel and in fuel cells to produce electricity on some spacecrafts. Together with the large energy content, hydrogen storage technologies exhibit also the possibility for a very long discharge time. Nevertheless, hydrogen storage technologies pose further challenges to the design of an onboard reservoir of the vehicle that is both reliable, light, small, affordable and rechargeable in a short time. At the moment none of the technologies fulfills simultaneously all these requirements. In particular, moving to satellite applications, the specifications become more severe: additionally to the previously listed features, the reservoir should be long lasting ( $\sim 10$ years), thus restricting even more the possible candidates among the plethora of materials usually suggested in the hydrogen storage community.

Two main approaches for hydrogen storage are known: a physical-based approach and a material-based approach. Within the first approach hydrogen is stored in its molecular form as compressed hydrogen, liquid hydrogen or cryocompressed hydrogen. Within the second approach hydrogen can be stored in materials either in its molecular form (physisorbed) or in its atomic form (chemisorbed). The first case (physisorption) is present in the sorption process within the porous materials (carbon nanostructures, metal organic frameworks, clathrates, etc). The interaction with the hydrogen gas in these materials is usually rather weak, allowing the storage of hydrogen without creating too strong bonds with the skeleton of the materials itself. Among these compounds there are microporous materials which are characterized by particular cage structures that make them as "sponges" able to store gases and, in particular, hydrogen. The second case (chemisorption) is present in the atomic hydrogen storage within metal hydrides, interstitial metallic or complex hydrides.

In the present work an alternative approach to select materials, based on developing a database and an application tool to query it, is suggested: an extensive collection of the most reliable data on candidate technologies and materials under various condition of pressure and temperatures, together with promoters, has been performed. The materials are eventually selected using proprietary tools in Python. In particular, the case of clathrate hydrates is reported as an example. This application allows to provide recommendations based on a vast variety of updated information and adopting a uniform methodology. The present work has thus a twofold aim: on one hand, we describe the approach for the query of databases to select materials for hydrogen storage; on the other hand, this methodology is applied to different kinds of materials, whereby it emerges that nanoporous materials can be suggested as good candidates in aerospace technologies for hydrogen storage. Specifically, the example of clathrates hydrates is reported here.
The paper is organized as follows: in Sect. 2 the method adopted for creating the database is presented, together with the collected data types, and the procedure implemented in the Python scripts to select the most suitable materials are described. As an example, the case of clathrates hydrates is reported: in Sect. 3.1 these compounds are described, and experimental and numerical performance data are provided. In Sect. 4 the relevant features are discussed in the framework of transport in aerospace applications and the major pro et contra are emphasized to justify the parameters adopted in the database query. They are also compared with the characteristics of physical storage of hydrogen, that are summarized in Appendix A.

\section{Methodology and data analysis}

A large amount of data materials characteristics for hydrogen storage are available in literature, resulting both from experimental measures and numerical simulations. To select the most performant materials for a specific application it is necessary to have a large database and a friendly tool to enquire it. Moreover, some assumptions are required in the case of multiple entries associated with a specific quantity of the database. Indeed, it can happen that measurements performed under different conditions or adopting different methods can lead to discrepancies in the results; the same holds for simulations. In this work, the first phase consisted in creating a database, after collecting a vast ensemble of information in the scientific literature. According to the material, the collected data is diverse, the relevant information being the material name, the operating temperatures (e.g., equilibrium, absorption, desorption, rehydration) and the pressures (absorption and desorption), sample size, maximum wt\% (theoretical and experimental), ${ }^{1} \Delta \mathrm{H}_{\text {desorption }}$, charge and discharge time, recyclability properties and bibliography. Eventually, the database entries have been modified so that, in the case of multiple values $N$ associated with a single entry, an arithmetic average of the available data has been performed. Zeros are assigned for those quantities for which no entry is found in literature. Queries on the modified database are then performed running the in-house developed Python scripts that use the library PANDAS, and that also allow to show the results as bar charts. ${ }^{2}$ Although a comprehensive work has been done on a larger ensemble

\footnotetext{
1 The gravimetric capacity of a material represents its capability to store hydrogen relative to its mass, while the volumetric capacity gives an estimate of the storing abilities respect to the unit volume of the material. The former is typically expressed in units $\mathrm{wt} \%$, or $\mathrm{kg}$ $\mathrm{H}_{2} \mathrm{~kg}^{-1}$, or mol $\mathrm{H}_{2} \mathrm{~kg}^{-1}$, while for the latter the units $\mathrm{kg} \mathrm{H}_{2} \mathrm{~m}^{-3}$ or mol $\mathrm{H}_{2} \mathrm{~m}^{-3}$ are usually adopted.

2 Python 3.5 has been used.
} 


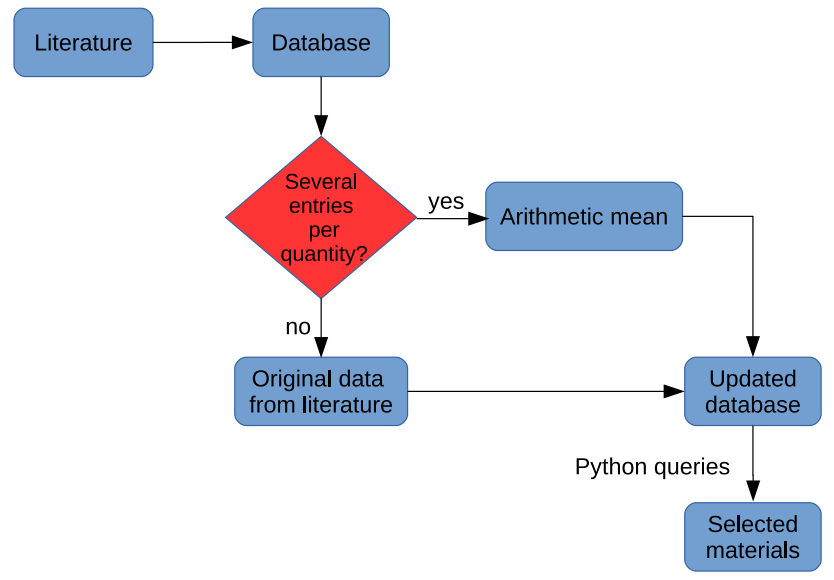

Fig. 1 Flowchart: materials selection and analysis, querying the database

of materials in the framework of the ESA project "Challenges related to the design of a reservoir for the transport of $\mathrm{H}_{2}$ " (including metal hydrides, organic liquids and MOFs), the model database presented and discussed here considers clathrates as good candidates in the context of aerospace applications as a fully detailed example. The present implementation is a demonstration, and future ones may make use of more advanced data such as those related to the quantum state of nanoconfined hydrogen species (Longo et al. 2018) and the kinetics of such species, also in their excited states (Longo et al. 2011; Esposito 2019; Coppola et al. 2016). Furthermore, molecular dynamics studies may help to test the limit of the Arrhernius Law in systems kinetics (Aquilanti et al. 2018).

The software developed for this work assumes that all information sources are equally reliable. Therefore, an arithmetic mean of the automatically detected data is used (Fig. 1). In future works, a reliability index $P_{i} \leq 1$ could be included for all sources and applied to new entries. A weighted average can then be used. In this way, a Bayesian decision is implemented (Cartwright 1993). In this perspective, our work merges with the research on the use of artificial intelligence (AI) in chemistry.

\section{Materials}

\subsection{Clathrate hydrogen hydrates}

Crystalline compounds in which host water molecules form cages around guest molecules and enclose them under favourable formation conditions of temperature and pressure are called clathrate hydrates (Englezos 1993). Clathrate hydrates of hydrogen are a new and promising direction for hydrogen storage. The $\mathrm{H}_{2}$ gas storage is carried out by trapping it through non-covalent weak bonds in water cages forming clathrates rather than through a chemical reaction followed by adsorption and desorption. The diameter of the hydrogen molecule $(2.72 \AA)$ was at first thought to be too small to make it part of a clathrate structure. Nevertheless, this assumption was challenged by experimental results. It was found that the mixture of $\mathrm{H}_{2}$ and $\mathrm{H}_{2} \mathrm{O}$ compressed at a pressure of $180-220 \mathrm{MPa}$ and cooled to $249 \mathrm{~K}$ forms a single solid compound. The energy-dispersive X-ray diffraction (EDXD) measurements have shown the existence of a face-centered cubic unit cell with $a=17.047 \pm 0.010 \AA$, in agreement with the sII clathrate structure (Mak and McMullan 1965). The proton peaks for hydrogen in the clathrate are corresponding in frequency to those of pure hydrogen, and the Raman spectroscopy proves that the hydrogen molecules in the clathrate cages are in free rotational states (Mao et al. 2002). This is a clear indication that hydrogen molecules remain unbonded in this kind of clathrates. Nonetheless, a considerable splitting and softening of the vibron peaks of hydrogen highlight some intermolecular interactions.

\subsubsection{Types of gas hydrate structures}

The kinetics of hydrate formation is driven either by the difference in operating temperature or operating pressure from the equilibrium conditions. The clathrates are nonstoichiometric and can form different crystalline structures depending on the guest molecules. Hydrogen-bonded water molecules form various polyhedral cages around guest molecules. The three common types of gas hydrate structures are: (1) the sI hydrate consisting of 46 water molecules that form two pentagonal dodecahedral $\left(5^{12}\right)$ and six tetrakaidecahedron $\left(5^{12} 6^{2}\right)$ cages in a unit cell, (2) the sII hydrate formed by 136 water molecules that form sixteen $5^{12}$ and eight $5^{12} 6^{4}$ cages in a unit cell, and (3) the sH hydrate consisting of 36 water molecules that form three $5^{12}$, two $4^{3} 5^{6}$ $6^{3}$, and one $5^{12} 6^{8}$ cages in a unit cell. These polyhedra are shown in Fig. 2. The size of the guest molecule affects the type of crystalline structure that can be formed around it. For instance, methane and ethane generate the sI hydrate, propane yields the sII hydrate, and cyclopentane, a much larger guest molecule, induces the production of the sH hydrate, in the presence of methane. If the guest molecule is ionic and its cationic part occupies the cages of hydrate structure like a guest while the anionic participates in the cage formation along with water, the semi-clathrate is formed (Bogdanović and Schwickardi 1997).

\subsubsection{Hydrogen storage without promoters}

Hydrogen storage without promoters can give quite high storage capacities, however, at very high pressures. A recent study (Willow and Xantheas 2012) calculated a gravimetric 

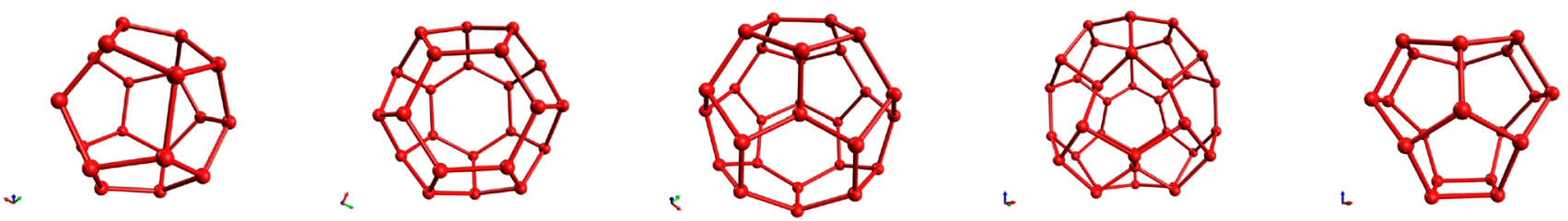

Fig. 2 Polyhedra that constitute the sI, sII and sH structures of hydrates clathrates. From left to right: $5^{12}, 5^{12} 6^{2}, 5^{12} 6^{4}, 5^{12} 6^{8}, 4^{3} 5^{6} 6^{3}$

density of $10 \mathrm{wt} \%$ for the sI hydrate with $5 \mathrm{H}_{2}$ molecules occupying dodecahedron cages and $7 \mathrm{H}_{2}$ molecules occupying tetrakaidecahedron cages. Nonetheless, this result has not been proven or validated experimentally. Another calculation predicted a gravimetric density of $3.81 \mathrm{wt} \%$ in the hypothesis that 4 molecules of $\mathrm{H}_{2}$ are per large cage and 1 molecule of $\mathrm{H}_{2}$ per small cage and $5.01 \mathrm{wt} \%$ in the hypothesis that the large cage contains 4 molecules of $\mathrm{H}_{2}$ and the small cage contains 2 molecules of $\mathrm{H}_{2}$ (Prasad et al. 2009), while experimentally the hydrogen storage was measured to be $5.3 \mathrm{wt} \%$ at $300 \mathrm{MPa}$ and $249 \mathrm{~K}$ (Mao and Mao 2004). The other practically advantageous option is the usage of ices. C2 ice experimentally shows a gravimetric density of $11.2 \mathrm{wt} \%$ at $2300 \mathrm{MPa}$ and $300 \mathrm{~K}$ (Mao and Mao 2004). The reactive ice Ic has the measured hydrogen capacity of 2.7 wt $\%$ at $15-18 \mathrm{MPa}$ and $140 \mathrm{~K}$, while according to the computations, it should be $10 \mathrm{wt} \%$ (Kumar et al. 2013). ${ }^{3}$ Very good results are shown by the ice-Ih (Lokshin et al. 2004; Kawamura et al. 2011): the formation of hydrogen clathrate from $\mathrm{H}_{2}$ gas and ice-Ih at 77-273 K occurs at least 100 times faster compared to the reaction with water $(3.77 \mathrm{wt} \%)$. A clathrate containing $\mathrm{H}_{2}$ at 1:1 ratio with water with a cubic diamond structure is stable only at very high pressures of at least $30000 \mathrm{MPa}$ (Vos et al. 1993).

\subsubsection{Usage of promoters}

The hydrogen clathrate is mostly stable due to the dispersive interactions between the molecules of hydrogen and water molecules of cage walls. The introduction of a second guest component into the hydrogen hydrate allows the storage of hydrogen at lower pressures; it was shown that the hydrogen is included into the clathrate framework in the presence of a second guest component (Holder et al. 1983; Zhang et al. 2000). Moreover, Raman spectroscopy measurements proved that all or most of the large cages of the binary clathrate hydrate are filled with the guest component, whereas the $\mathrm{H}_{2}$ molecules most likely occupy to a

\footnotetext{
3 The discrepancy can be justified considering difficulty in reproducing the exact crystallographic structure for the experimental data and the most likely presence of a mixture of different kinds of crystals in the experiment.
}

significant extent only the small cages (Florusse et al. 2004). The inclusion of guest molecules usually, but not always, fills the larger cavities, and their presence also leads to a significant decrease in the capacity of hydrogen storage, yet at the same time decreases considerably the formation pressure. The potential for hydrogen storage was investigated in a variety of novel binary clathrates. For example, it was calculated that the addition of 1,1-dimethylcyclohexane (1,1$\mathrm{DMCH})$ stabilizes the sH clathrate. However, it reduces the gravimetric density significantly, down to $1.37 \%$ with an arrangement of 0 and 1 molecules of $\mathrm{H}_{2}$ per large and small cages, respectively (Prasad et al. 2009). The low amount of absorbed hydrogen storage $(0.028 \mathrm{~mol} / \mathrm{mol})$ produced in the cage with the promoter 1,3-dioxolane at $10 \mathrm{MPa}$ and $233 \mathrm{~K}$ demonstrates distinctly that the inclusion of hydrogen atoms within empty small cages changes the size of the host cages depending on the type of guest molecule (Kawamura et al. 2011). It was shown that the increase of percentage of 1,4-dioxane from 0.2 to $5.56 \mathrm{~mol} \%$ in powdered dioxane hydrates leads to the drop in hydrogen capacity from 1.1 down to $0.4 \mathrm{wt} \%$ at $12 \mathrm{MPa}$ and $233 \mathrm{~K}$ (Yoon et al. 2008; Kawamura et al. 2011). The study (Sugahara et al. 2010) investigated the dependency of large cages occupancies on pressures and guest concentrations succeeding to increase the gravimetric density of hydrogen up to $3.6 \pm 0.1 \mathrm{wt} \%$ by means of addition of acetone $(0.58 \mathrm{~mol} \%)$ at $74 \mathrm{MPa}$ and $255 \mathrm{~K}$. In this study the hydrates were formed from the self-assembly of solid promoter and powdered ice. Formation of cyclopentane-hydrogen clathrate hydrates from powder (mole ratio of cyclopentane to water 1:17) in constant volume and temperature at $2.0^{\circ} \mathrm{C}$ and initial pressure of 10-18 MPa has shown a hydrogen storage capacity of $0.27 \mathrm{wt} \%$ (Saha and Deng 2010). Powdered furan hydrates (5.6 mol\%) pressurized with hydrogen yield storage capacities much greater than that of tetrahydrofuran hydrate in spite of the same crystal structure (sII). The storage amount of hydrogen at $275.1 \mathrm{~K}$ is about $1.2 \mathrm{~mol}$ (hydrogen)/mol (tetrahydrothiophene or furan hydrate) $(\sim 0.6$ mass $\%)$ at $41.5 \mathrm{MPa}$, which is coincident with that of tetrahydrofuran hydrate (Tsuda et al. 2009). The hydroquinone clathrate has been recognized as one of the potential host media for hydrogen storage, because it often forms stable cage-like structures at ambient conditions. The $\mathrm{CO}_{2}$ loaded hydroquinone clathrates lose the gaseous promoter upon heating, 
forming cages able to adsorb and desorb hydrogen rapidly with only a marginal degradation. The gravimetric hydrogen storage capacities were found to be 0.38 and $0.19 \mathrm{wt} \%$ at 35 and $10 \mathrm{MPa}$, respectively, while the calculated value is $0.61 \mathrm{wt} \%$ (Han et al. 2012). However, the thermodynamically favorable beta-phase hydroquinone was found to form clathrates enclosing gas molecules like hydrogen and methane. Upon the dehydrogenation of the host lattice via the oxidation of hydroquinone to benzoquinone, the measured release of hydrogen suggested a $2.43 \mathrm{wt} \%$ hydrogen capacity for both guest host materials (Strobel et al. 2008). Powdered propane hydrates pressurized with the hydrogen clathrate sII structure yield $0.02-0.33 \mathrm{wt} \%$ at $0.67-12 \mathrm{MPa}$ and 263-270 K (Park and Lee 2007; Abbondondola et al. 2010), while the amount of encaged hydrogen in $\mathrm{H}_{2}$-propylene oxide $(0.029 \mathrm{~mol} / \mathrm{mol})$ was found to be comparable to that of $\mathrm{H}_{2}$-THF binary hydrate. Moreover, it was found that the trend of the changes for lattice constants is not related to the amount of encaged $\mathrm{H}_{2}$. These results suggest that the organic compounds investigated can be used as alternatives to THF for the hydrogen enclathration (Kawamura et al. 2011). It was found that a variety of large molecules with butyl group have a stabilizing effect in binary hydrogen clathrates. The experiment has shown that the $5.56 \mathrm{~mol} \%$ concentration of tertbutylamine yields $0.7 \mathrm{wt} \%$ at $13.8 \mathrm{MPa}$ and $250 \mathrm{~K}$ (Prasad et al. 2009). The calculations demonstrate that the gravimetric density varies in the range $0.61-5.18$ wt (Prasad et al. 2009). A gravimetric content of $5.18 \mathrm{wt} \%$ is produced when a cluster of six $\mathrm{H}_{2}$ molecules partially occupies the large cages of sVI type (McMullan et al. 1967). On the other hand, the tetrabutylammonium (TBA) halides give very good hydrogen storage capacities: the bromide (concentration $2.71 \mathrm{~mol} \%$ ), chloride (3.26 mol\%), fluoride (3.4 mol\%) species give the capacities of $0.22,0.12,0.024$ wt\%, respectively (Trueba et al. 2012; Strobel et al. 2007; Deschamps and Dalmazzone 2010; Trueba et al. 2013). The complex tetrabutylphosphonium bromide with the concentration of $3.04 \mathrm{~mol} \%$ yields a gravimetric density of $0.14 \mathrm{wt}$ (Deschamps and Dalmazzone 2010). Other promising butylammonium-based promoters are tetrabutylammonium polyacrylate (with the cross linking ratio of $0.5 \%$ ) (Aladko et al. 2010; Skiba et al. 2008), tetrabutylammoniumborohydride (2.54 mol \%) (Shin et al. 2009), and methyl-tert-butyl ether (Prasad et al. 2009). The last two stabilizing agents yield relatively high hydrogen storage capacities (1.35 and $1.42 \mathrm{wt} \%$, respectively). Another very well studied and promising promoter for hydrogen clathrate stabilization is tetrahydrofuran (THF), whose addition drastically decreases the formation pressure (Kawamura et al. 2011; Prasad et al. 2009; Lee et al. 2005; Veluswamy and Linga 2013; Nagai et al. 2008; Ogata et al. 2008; Yoshioka et al. 2011; Arca et al. 2008). The hydrogen storage capacities in THF- containing binaryclathrate hydrates can be increased up to $4.03 \mathrm{wt} \%$ at modest

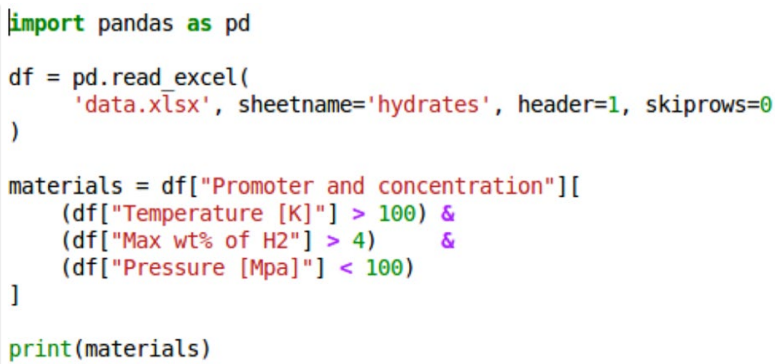

Fig. 3 Database loading and query: the case of clathrates hydrates. The Python script uses the library PANDAS

pressures by tuning their composition to allow the hydrogen guests to enter both the larger and the smaller cages, while retaining low-pressure stability. The tuning mechanism is quite general and convenient, using water-soluble hydrate promoters and various small gaseous guests. The THF concentration of $0.15 \mathrm{~mol} \%$ gives the highest gravimetric density 4.03 (wt\%) at $12 \mathrm{MPa}$ and $270 \mathrm{~K}$ (Lee et al. 2005). It was also shown that a $5.0 \mathrm{~mol} \%$ concentration of THF stabilizes at $5 \mathrm{MPa}$ and $279 \mathrm{~K}$ with $4 \mathrm{wt} \%$ (Florusse et al. 2004). These results are explained by the double occupancy of small cavities by $\mathrm{H}_{2}$ and by the partial occupation of large cavities by THF. Various materials were investigated as a possible support for the $\mathrm{THF}-\mathrm{H}_{2}$ enclathration: polymerized high internal phase emulsion (polyHIPE) (Su et al. 2008), mesoporous carbon (Saha and Deng 2009), polyacrylic sodium salt (Su et al. 2009), ice (Strobel et al.2006; Anderson et al. 2007; Talyzin 2008; Sugahara et al. 2010), solid THF (Sugahara et al. 2009), polyurethane foam (Talyzin 2008), porous media of silica gel (Saha and Deng 2010). The conclusion was drawn that the choice of a support material greatly affects the clathrate synthesis process.

\section{Materials selection}

According to the data collected in this paper we have proceeded in the selection of clathrates hydrates by considering the possible version for this class of materials for which the gravimetric storage capacity is above 4, the desorption temperature is above $100 \mathrm{~K}$ and the working pressures are below $100 \mathrm{MPa}$ These features are obtained by restricting the query to the database as reported in Figure 3. The clathrate hydrates sheet contains around 80 different species, corresponding to diverse promoters, pressure and temperature conditions; in the same sheet, the corresponding references can also be found as additional information to navigate among all the data. The materials which satisfy these requirements among clathrates are: $\mathrm{H}_{2} \mathrm{O}$ molecules without promoter@16.5 MPa, $140 \mathrm{~K}$ and THF/0.15 mol. As a comparison, another material which shows as good performances 
among nanoporous materials is PCN-68 (NOTT-116), considering gravimetric and volumetric storage capacities above 1.1 and 4.3 at RT, respectively, and pressures above 70 bar.

Hydrogen physisorption has several advantages compared to chemisorption; it is worth to specifically mention its fast sorption kinetics, full reversibility and high stability over many cycles (Ramimoghadam et al. 2016; Goldsmith et al. 2013). Moreover, in the case of MOFs, changes in the compound structures during (ab)desorption cycles is not observed, therefore, allowing for a good cyclability. Specifically, however, these advantages are at the expense of the low operational temperatures (Lai et al. 2015) (although ongoing research is focused on increasing $\mathrm{H}_{2}$ adsorption enthalpy thus improving this issue).

The successful synthesis of hydrogen hydrate clathrates is a definite advancement in the development of materials for hydrogen storage. Opposite to the conventional hydrogen storage materials, the hydrogen hydrates do not ignite easily nor corrode, thus provide an environmentally friendly and safe material to store hydrogen. It is still a challenge to employ hydrogen hydrates as practical materials for hydrogen storage. The synthesis of hydrogen hydrates is a relatively slow process since their formation is controlled by diffusion through a bulk solid phase. This recognized issue can be overcome by taking advantage of nanoemulsion methods as those recently described in the literature (Profio et al. 2018). Both pressure and temperature are controlled to achieve their formation. The slow kinetics may create difficulties for the effective recharging of hydrogen storage devices. That is why, one of the most important features of the hydrogen storage based on clathrates is the rate of clathrate synthesis. Permanent cooling, which is necessary to keep hydrogen hydrates stable, may be another issue. If the cooling stalls, the large amounts of hydrogen will be released by the material in a short time, which leads to safety problems. Thus, the higher capacities can be achieved only via the investigation of new structures of hydrogen hydrates with promoters. The only drawback in the addition of a thermodynamic promoter is the decrease of hydrogen storage capacity, since the added promoter also occupies the cages in hydrate structure. Thus, there is a trade-off between the hydrogen storage capacity and the hydrate formation conditions. It was observed that there is a tuning effect in some binary hydrogen clathrates that reduces the promoter concentration and augments the hydrogen storage capacity (Lee et al. 2005; Koh et al. 2013).
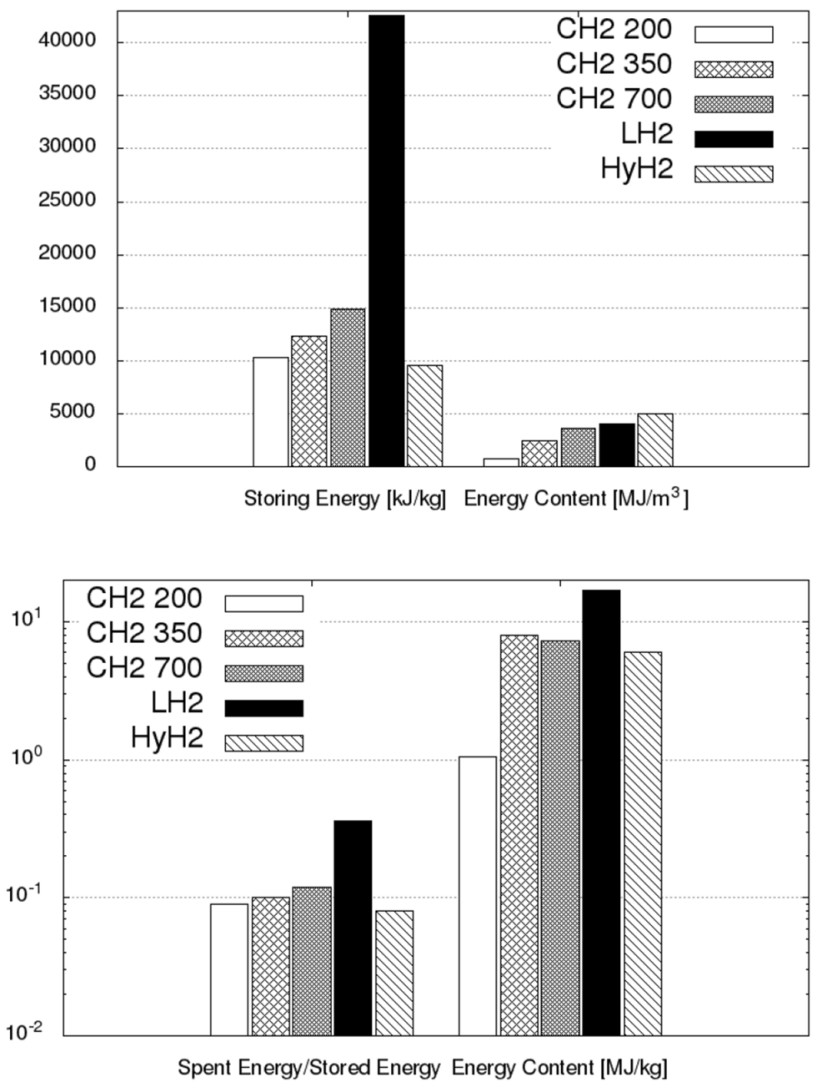

Fig. 4 Storing features of clathrates hydrates compared to physical hydrogen storage and other compounds used for hydrogen storage (adapted from (Di Profio et al. 2009)). For completeness, both gravimetric and volumetric capacities are reported. The acronyms stand for: $\mathrm{CH} 2$ compressed hydrogen (pressure in bar), LH2 liquid hydrogen, $\mathrm{HyH} 2$ clathrate hydrates. From the data reported in the figure, it is possible to estimate the Specific Energy Consumption (SEC). In terms of SEC the net energy in such systems is comparable with the other technologies which have the highest volumetric and/or gravimetric densities. The net energy is defined as the difference between the energy necessary to store hydrogen and the energy required to release it. In the case of liquid hydrogen (LH2) the value $16.81 \mathrm{MJ} /$ $\mathrm{kg}$ has been derived considering the experimental tank rather than the theoretical value. In fact, a net energy content of $14 \%$ of the theoretical value is usually experimentally found

Considering the net efficiencies and the greenhouse gases production, the storage through clathrates hydrates can be considered as a reversible environment-friendly procedure, as shown in Di Profio et al. (2009) (Fig. 4). 


\section{Clathrates hydrates}

Pro:

1. rapid kinetics and green chemistry;

2. full reversibility of $\mathrm{H}_{2}$ adsorption and desorption processes; Contra:

1. volumetric capacities relatively low (compared to metal hydrides) and gravimetric capacities at RT do not generally exceed $2 \mathrm{wt} \%$ even at high (20 MPa) pressures

Highly compressed gas

Pro:

1. no need to cool the gas to very low temperatures; Contra:

1. relatively modest volumetric densities ( $36 \mathrm{~g} / \mathrm{l}$ at $800 \mathrm{bar}$ and at room temperature);

2. high pressures needed;

3. large volumes;

4. energy loss during the pressurization process (12-16\% for compression at 800 bar);

5. safety risks

Liquid hydrogen

Pro:

1. high volumetric density (70 g/l @ 1 atm and @ 20 K);

2. no need for high pressures Contra:

1. maintenance of cryogenic conditions/hydrogen boil-off;

2. 30\%-35\% of energy value required for liquefaction (3 times more than highly compressed gas);

3. safety risks

Cryo-compressed

Pro:

1. highest volumetric density (87 g/1 @ 240 bar and @ $20 \mathrm{~K})$;

2. reduced boil-off and dormancy time in pressurized vessels. Contra:

1. net energy to be reduced by the compression and the liquefaction works performed to the system

\section{Conclusions}

A comprehensive analysis of the possible candidates for hydrogen storage applications to satellite technology and, more in general, aerospace applications, has been collected in a database. In particular, together with physical storage achieved through liquid, highly compressed and cryo-compressed hydrogen, materials with intrinsic porosity can be suggested for aerospace applications due to their cyclabilities and weight compared to other technologies (like metal hydrides) generally adopted in automotive research and development. The costs for the production of these materials and their low polluting effect represent also an advantage when designing a reservoir for the transport of hydrogen. The selection has been performed via an alternative database approach where the queries can be easily managed. An extensive database containing information on the synthesis, the operating temperature and pressure, together with the volumetric and gravimetric capacities has been collected. In view of the extreme requirements to storage in the space transport context, the authors believe that this information is of high value also as guideline for application in the automotive context, especially when extending to other nanoporous materials like MOFs.

Acknowledgements The Authors acknowledge ESA for funding the contract "Challenges related to the design of a reservoir for the transport of $\mathrm{H}_{2}$ ". C. M. C acknowledges Regione Puglia for the project "Intervento cofinanziato dal Fondo di Sviluppo e Coesione 2007-2013 - APQ Ricerca Regione Puglia - Programma regionale a sostegno della specializzazione intelligente e della sostenibilità sociale ed ambientale - FutureInResearch".

\section{Compliance with ethical standards}

Conflict of interest The authors declare no competing financial interest.

Ethical statement The authors guarantee the compliance with the Ethics Guidelines of the journal.

\section{Appendix: Highly compressed, liquid hydrogen and cryo-compressed storage}

The phase diagram of hydrogen shows several interesting behaviours according to the temperature and pressure ranges. At normal condition of temperature and pressure, hydrogen exists in gas state. Decreasing the temperature and/or increasing the pressure leads to the phase transition to liquid and to solid. Four different insulating molecular crystal phases have been observed for increasing pressure. Moreover, metallic hydrogen has been recently found as a new phase of matter, that shows to be superfluid and superconductor; it is expected to be found in the interior of gas giants as Jupiter. The characteristic temperatures for hydrogen (critical temperature, boiling point and melting temperature) are quite low compared to other elements $(32.976 \mathrm{~K}$, $20.28 \mathrm{~K}$ and $13.81 \mathrm{~K}$, respectively). Eventually, an important role is played by quantum mechanics and statistical mechanics in the description of phase transitions, especially the gas to liquid one. In particular, the technological problems connected to the liquefaction of hydrogen can be understood in the framework of nuclear spins statistics. Historically, the discovery of different nuclear states has been argued and inferred studying the experimental curve of the specific heat of hydrogen. Indeed, molecular hydrogen can be found in two distinct nuclear configurations, labelled as ortho and para and corresponding respectively to odd and even rotational quantum numbers. 
Highly compressed hydrogen gas At room temperature (RT), hydrogen gas is described by a van der Waals-like equation of state; indeed, it behaves as a non-ideal gas because of the strong repulsive interaction among $\mathrm{H}_{2}$ molecules. ${ }^{4}$ Hydrogen is stored as highly compressed gas in particular cylinders that can endure pressures up to $80 \mathrm{MPa}$ for composite materials tanks (20 MPa for steel ones). The variation in pressure $\Delta p$ across the tank wall (also referred to as tank gauge pressure) depends on the geometry of the cylinder (specifically on the thickness of the wall $t_{w}$ and of the total cylinder diameter $\left.t_{o}\right)$ and on a parameter $\left(\sigma_{v}\right.$, called tensile strength) that is specific of the materials the cylinder is made of. In particular the following relation holds:

$\Delta p=2 \sigma_{v}\left(\frac{t_{o}}{t_{w}}-1\right)^{-1}$

hydrogen volumetric density around

The tensile strength varies according to the material, assuming values that are of the order of $50 \mathrm{MPa}$ for aluminum, $1100 \mathrm{MPa}$ for high quality steel and $2410 \mathrm{MPa}$ in the case of boron. In designing a cylinder for highly compressed gas, the higher the tensile strength, the better is the material in terms of performances; moreover, the material should be light to prevent the tank to be heavy. At the moment, the maximum tank pressure that has been achieved corresponds to $80 \mathrm{MPa}$, which corresponds to a hydrogen volumetric density around $36 \mathrm{~kg} \cdot \mathrm{m}^{-3}$ (Zuttel 2003).

Cryogenic liquid hydrogen At normal pressure condition, hydrogen gas can be liquefied by cooling the system down to the boiling point $(20.28 \mathrm{~K})$. The cooling process for gases usually requires cycles in which the system is firstly compressed, isoenthalpically and, subsequently, it is expanded. Typically, at RT, gases (e.g., nitrogen) warm upon compression and cool during the expansion ${ }^{5}$; this is called the Joule-Thomson effect and it is used in the Linde cycle to reach cryogenic temperatures. However, for $\mathrm{H}_{2}$, as well as for $\mathrm{He}$ and $\mathrm{Ne}$, the gas warms upon expansion. For this reason, the system must be cooled down below the inversion temperature at the corresponding operating pressure; from that moment on, the regular Linde cycle can be applied to reach lower temperatures. In the case of hydrogen, the maximum inversion temperature is $202 \mathrm{~K}$ at $0 \mathrm{~atm}$. For this reason, to start with higher pressure and eventually expand the gas, the hydrogen is pre-cooled down to $78 \mathrm{~K}$ by means of liquid nitrogen (that is eventually recycled in the refrigeration loop).

\footnotetext{
${ }^{4}$ The repulsion among molecules is also responsible for the low critical temperature of hydrogen (corresponding to $32.967 \mathrm{~K}$ ).

5 In general these features depend on the temperatures at which the variation of the volume takes place.
}

The experimental amount of energy required in the process of hydrogen liquefaction at RT is $W_{\text {exp }} \sim 15.2 \mathrm{kWh} \mathrm{kg}^{-1}$ (Zuttel 2003). An important aspect that limits and mines the overall efficiency relies on the boil-off rate of hydrogen from a liquid storage vessel; this is due to heat leaks, that depend on the geometry of the tank (size and shape) and on the thermal insulation applied. Since boil-off losses caused by heat leaks are proportional to the surface-to-volume ratio, as the size of the vessel increase, the evaporation rate decreases. In terms of orders of magnitude, in the case of doubly-walled vacuum-insulated tanks with spherical geometry, boil-off losses are typically $0.4 \% /$ day, $0.2 \%$ day and $0.06 \%$ /day for volumes of $50 \mathrm{~m}^{3}, 100 \mathrm{~m}^{3}$ and $20000 \mathrm{~m}^{3}$, respectively (Zuttel 2003).

Together with these technological aspects, there are important effects on the gas-liquid phase transition due to the conversion between the ortho- to para- hydrogen species. They represent a special rearrangement of nuclear spins (parallel and antiparallel respectively). The distribution of ortho- and para-hydrogen is a key element to describe possible heat loss deriving from the conversion in between these two nuclear spin arrangements (Dunlap 2014) ; having a proper description of the ortho- to-para ratio would give a more precise estimate of the heat transfer and a better technological design can eventually be suggested (and it will part of following tasks of the present project).

Cryo-compressed storage The cryo-compressed storage is a mixed approach between the highly compressed gas and the cryogenic storage technologies. The volumetric density obtained in such condition can easily reach $87 \mathrm{~g} / \mathrm{l}$, alleviating also the boil-off problem and allowing, at the moment, for the longest driving distance with a single tank in the automotive application. This efficiency corresponds to 5.8 wt $\%$ and $43 \mathrm{~g} \mathrm{H}_{2} /{ }^{6}{ }^{6}$

\section{References}

Abbondondola JA, Fleischer EB, Janda KC (2010) Comparative study of hydrogen, argon, and xenon uptake into a propane hydrate. AIChE J 56(10):2734

Ahluwalia R, Hua T, Peng JK, Lasher S, McKenney K, Sinha J, Gardiner M (2010) Technical assessment of cryo-compressed hydrogen storage tank systems for automotive applications. Int J Hydrog Energy 35(9):4171. https://doi.org/10.1016/j.ijhyd ene.2010.02.074. http://www.sciencedirect.com/science/article/ pii/S0360319910003563

Aladko EY, Larionov E, Manakov AY, Terekhova I (2010) Double clathrate hydrates of cross-linked tetrabutylammonium polyacrylate and noble gases at high pressures. J Inclus Phenom Macrocyclic Chem 67(1-2):13

\footnotetext{
6 These values are typical for compression corresponding to $275 \mathrm{bar}$ with the available thickness of the tank's walls and system's volume $\sim 1301$ (Ahluwalia et al. 2010).
} 
Anderson R, Chapoy A, Tohidi B (2007) Phase relations and binary clathrate hydrate formation in the system $\mathrm{H} 2-\mathrm{THF}-\mathrm{H} 2 \mathrm{O}$. Langmuir 23(6):3440

Aquilanti V, Borges EP, Dantas Coutinho N, Mundim KC, CarvalhoSilva V (2018) From statistical thermodynamics to molecular kinetics: the change, the chance and the choice. Rend Fis Acc Lincei. https://doi.org/10.1007/s12210-018-0749-9

Arca S, Di Profio P, Germani R, Savelli G (2008) Method for the production of binary clathrate hydrates of hydrogen. Eur Patent 2160352:A2

Bogdanović B, Schwickardi M (1997) Ti-doped alkali metal aluminium hydrides as potential novel reversible hydrogen storage materials. J Alloys Compd. 253:1

Cartwright H (1993) Applications of artificial intelligence in chemistry. Oxford Science Publications (Oxford University Press). https://books.google.it/books?id=etPvAAAAMAAJ

Coppola C, Mizzi G, Bruno D, Esposito F, Galli D, Palla F, Longo $\mathrm{S}$ (2016) State-to-state vibrational kinetics of $\mathrm{H} 2$ and $\mathrm{H}+2$ in a post-shock cooling gas with primordial composition. Mon Not R Astron Soc 457(4):3732. https://doi.org/10.1093/mnras /stw198. https://www.scopus.com/inward/record.uri?eid=2s2.0-84963877303\&doi $=10.1093 \% 2 \mathrm{fmnras} \% 2 \mathrm{fstw} 198 \&$ partn erID $=40 \&$ md5 $=$ baf36bdcdf4ff $8 \mathrm{f} 28 \mathrm{f} 4 \mathrm{df} 4 \mathrm{a} 8 \mathrm{~d} 76 \mathrm{e} 0 \mathrm{cb} 6$

Deschamps J, Dalmazzone D (2010) Hydrogen storage in semiclathrate hydrates of tetrabutyl ammonium chloride and tetrabutyl phosphonium bromide. J Chem Eng Data 55(9):3395

Di Profio P, Arca S, Rossi F, Filipponi M (2009) Comparison of hydrogen hydrates with existing hydrogen storage technologies: energetic and economic evaluations. Int J Hydrog Energy 34:9173. https://doi.org/10.1016/j.ijhydene.2009.09.056

Dunlap R (2014) Sustainable energy. Sustain Energy (Cengage Learning). https://books.google.it/books?id=cufKAgAAQBAJ

Englezos P (1993) Clathrate hydrates. Ind Eng Chem Res 32(7):1251

Esposito F (2019) Reactivity, relaxation and dissociation of vibrationally excited molecules in low-temperature plasma modeling. Rend Fis Acc Lincei. https://doi.org/10.1007/s12210-019-00778-9

Florusse LJ, Peters CJ, Schoonman J, Hester KC, Koh CA, Dec SF, Marsh KN, Sloan ED (2004) Stable low-pressure hydrogen clusters stored in a binary clathrate hydrate. Science 306(5695):469

Goldsmith J, Wong-Foy AG, Cafarella MJ, Siegel DJ, (2013) Theoretical limits of hydrogen storage in metal-organic frameworks: opportunities and trade-offs. Chem Mater 25(16): 3373. https:// doi.org/10.1021/cm401978e. http://dx.doi.org/10.1021/cm401 978e

Han KW, Lee YJ, Jang JS, Jeon TI, Park J, Kawamura T, Yamamoto Y, Sugahara T, Vogt T, Lee JW et al (2012) Fast and reversible hydrogen storage in channel cages of hydroquinone clathrate. Chem Phys Lett 546:120

Holder GD, Stephenson JL, Joyce JJ, John VT, Kamath VA, Malekar S (1983) Formation of clathrate hydrates in hydrogen-rich gases. Ind Eng Chem Process Des Dev 22(1):170

Kawamura T, Takeya S, Ohtake M, Yamamoto Y (2011) Enclathration of hydrogen by organic-compound clathrate hydrates. Chem Eng Sci 66(11):2417

Koh DY, Kang H, Lee H (2013) Multiple guest occupancy in clathrate hydrates and its significance in hydrogen storage. Chem Commun 49(60):6782

Kumar R, Klug DD, Ratcliffe CI, Tulk CA, Ripmeester JA (2013) Lowpressure synthesis and characterization of hydrogen-filled ice Ic. Angew Chem 125(5):1571

Lai Q, Paskevicius M, Sheppard DA, Buckley CE, Thornton AW, Hill MR, Gu Q, Mao J, Huang Z, Liu HK, Guo Z, Banerjee A, Chakraborty S, Ahuja R, Aguey-Zinsou KF (2015) Hydrogen storage materials for mobile and stationary applications: current state of the art. ChemSusChem 8(17):2789. https://doi.org/10.1002/ cssc. 201500231
Lee H, Lee JW, Park J, Seo YT, Zeng H, Moudrakovski IL, Ratcliffe CI, Ripmeester JA et al (2005) Tuning clathrate hydrates for hydrogen storage, tuning clathrate hydrates for hydrogen storage. Nature 434(7034):743

Lokshin KA, Zhao Y, He D, Mao WL, Mao HK, Hemley RJ, Lobanov MV, Greenblatt M (2004) Structure and dynamics of hydrogen molecules in the novel clathrate hydrate by high pressure neutron diffraction. Phys Rev Lett 93(12): 125503

Longo S, Micca Longo G, Giordano D (2018) Monte Carlo calculation of the potential energy surface for octahedral confined $\mathrm{H}_{2}^{+}$. Rend Fis Acc Lincei 29:173. https://doi.org/10.1007/s1221 $0-018-0666-y$

Longo S, Coppola C, Galli D, Palla F, Capitelli M (2011) The role of vibrationally excited molecules in the chemistry of the early Universe molecular hydrogen and its cation. Rend Fis Acc Lincei 22(2):119. https://doi.org/10.1007/s12210-0110119-3. https://www.scopus.com/inward/record.uri?eid=2s2.0-80051673062\&doi=10.1007\%2fs12210-011-0119-3\&partn erID $=40 \& m d 5=92139055 \mathrm{a} 4 \mathrm{dc} 5 \mathrm{~d} 2 \mathrm{dcb} 3 \mathrm{c} 13 \mathrm{~b} 7 \mathrm{e} 806 \mathrm{e} 9 \mathrm{e} 3$

Mak TC, McMullan RK (1965) Polyhedral clathrate hydrates. X. Structure of the double hydrate of tetrahydrofuran and hydrogen sulfide. J Chem Phys 42(8):2732

Mao WL, Mao HK (2004) Hydrogen storage in molecular compounds. Proc Natl Acad Sci USA 101(3):708

Mao WL, Mao Hk, Goncharov AF, Struzhkin VV, Guo Q, Hu J, Shu J, Hemley RJ, Somayazulu M, Zhao Y (2002) Hydrogen clusters in clathrate hydrate. Science 297(5590):2247

McMullan R, Jeffrey G, Jordan TH (1967) Polyhedral clathrate hydrates. XIV. The structure of (CH3) 3CNH2 93/4H2O. J Chem Phys 47(4): 1229

Nagai Y, Yoshioka H, Ota M, Sato Y, Inomata H, Smith RL, Peters CJ (2008) Binary hydrogen-tetrahydrofuran clathrate hydrate formation kinetics and models. AIChE J 54(11):3007

Ogata K, Hashimoto S, Sugahara T, Moritoki M, Sato H, Ohgaki K (2008) Storage capacity of hydrogen in tetrahydrofuran hydrate. Chem Eng Sci 63(23):5714

Park J, Lee H (2007) Spectroscopic evidences of the double hydrogen hydrates stabilized with ethane and propane. Korean J Chem Eng 24(4):624

Prasad PS, Sugahara T, Sum AK, Sloan ED, Koh CA (2009) Hydrogen storage in double clathrates with tert-butylamine. J Phys Chem A 113(24):6540

Profio PD, Canale V, Germani R, Arca S, Fontana A (2018) J Colloid Interface Sci 516:224. https://doi.org/10.1016/j.jcis.2018.01.059. http://www.sciencedirect.com/science/article/pii/S002197971 8300687

Ramimoghadam D, Gray EM, Webb C (2016) Review of polymers of intrinsic microporosity for hydrogen storage applications. Int J Hydrog Energy 41(38):16944. https://doi.org/10.1016/j.ijhyd ene.2016.07.134. http://www.sciencedirect.com/science/article/ pii/S0360319916303433

Saha D, Deng S (2009) Enhanced hydrogen adsorption in ordered mesoporous carbon through clathrate formation. Int J Hydrog Energy 34(20):8583

Saha D, Deng S (2010) Accelerated Formation of THF-H2 clathrate hydrate in porous media. Langmuir 26(11):8414

Shin K, Kim Y, Strobel TA, Prasad P, Sugahara T, Lee H, Sloan ED, Sum AK, Koh CA (2009) Tetra-n-butylammonium borohydride semiclathrate: a hybrid material for hydrogen storage. J Phys Chem A 113(23):6415

Skiba SS, Terekhova IS, Larionov EG, Manakov AY (2008) Incorporation of gas molecules into the frameworks of clathrate hydrates of ion-exchange resins in tetraalkylammonium form. Mendeleev Commun 18(3):126 
Strobel TA, Taylor CJ, Hester KC, Dec SF, Koh CA, Miller KT, Sloan E (2006) Molecular hydrogen storage in binary THF-H2 clathrate hydrates. J Phys Chem B 110(34):17121

Strobel TA, Koh CA, Sloan ED (2007) Hydrogen storage properties of clathrate hydrate materials. Fluid Phase Equilib 261(1):382

Strobel TA, Kim Y, Andrews GS, Ferrell Iii JR, Koh CA, Herring AM, Sloan ED (2008) Chemical-clathrate hybrid hydrogen storage: storage in both guest and host. J Am Chem Soc 130(45):14975

Su F, Bray CL, Tan B, Cooper AI (2008) Rapid and reversible hydrogen storage in clathrate hydrates using emulsion-templated polymers. Adv Mater 20(14):2663

Su F, Bray CL, Carter BO, Overend G, Cropper C, Iggo JA, Khimyak YZ, Fogg AM, Cooper AI (2009) Reversible hydrogen storage in hydrogel clathrate hydrates. Adv Mater 21(23):2382

Sugahara T, Haag JC, Prasad PS, Warntjes AA, Sloan ED, Sum AK, Koh CA (2009) Increasing hydrogen storage capacity using tetrahydrofuran. J Am Chem Soc 131(41):14616

Sugahara T, Haag JC, Warntjes AA, Prasad PS, Sloan ED, Koh CA, Sum AK (2010) Large-cage occupancies of hydrogen in binary clathrate hydrates dependent on pressures and guest concentrations. J Phys Chem C 114(35): 15218

Talyzin A (2008) Feasibility of H2-THF-H2O clathrate hydrates for hydrogen storage applications. Int J Hydrog Energy 33(1):111

Trueba AT, Radović IR, Zevenbergen JF, Kroon MC, Peters CJ (2012) Kinetics measurements and in situ Raman spectroscopy of formation of hydrogen-tetrabutylammonium bromide semi-hydrates. Int J Hydrog Energy 37(7):5790

Trueba AT, Radović IR, Zevenbergen JF, Peters CJ, Kroon MC (2013) Kinetic measurements and in situ Raman spectroscopy study of the formation of TBAF semi-hydrates with hydrogen and carbon dioxide. Int J Hydrog Energy 38(18):7326

Tsuda T, Ogata K, Hashimoto S, Sugahara T, Moritoki M, Ohgaki K (2009) Storage capacity of hydrogen in tetrahydrothiophene and furan clathrate hydrates. Chem Eng Sci 64(19):4150

Veluswamy HP, Linga P (2013) Macroscopic kinetics of hydrate formation of mixed hydrates of hydrogen/tetrahydrofuran for hydrogen storage. Int J Hydrog Energy 38(11):4587

Vos WL, Finger LW, Hemley RJ, Mao HK (1993) Novel $\mathrm{H}_{2}-\mathrm{H}_{2} \mathrm{O}$ clathrates at high pressures. Phys Rev Lett 71(19):3150

Willow SY, Xantheas SS (2012) Enhancement of hydrogen storage capacity in hydrate lattices. Chem Phys Lett 525:13

Yoon JH, Han J, Park J, Choi S, Yeon SH, Lee H (2008) Spectroscopic identification, thermodynamic stability and molecular composition of hydrogen and 1,4-dioxane binary clathrate hydrate. J Phys Chem Solids 69(5): 1432

Yoshioka H, Ota M, Sato Y, Watanabe M, Inomata H, Smith RL, Peters CJ (2011) Decomposition kinetics and recycle of binary hydrogen-tetrahydrofuran clathrate hydrate. AIChE J 57(1):265

Zhang SX, Chen GJ, Ma CF, Yang LY, Guo TM (2000) Hydrate formation of hydrogen+ hydrocarbon gas mixtures. J Chem Eng Data 45(5):908

Zuttel A (2003) Materials for hydrogen storage. Materi Today 6(9):24. https://doi.org/10.1016/S1369-7021(03)00922-2. http://www. sciencedirect.com/science/article/pii/S1369702103009222

Publisher's Note Springer Nature remains neutral with regard to jurisdictional claims in published maps and institutional affiliations. 